

\title{
Perception of Patients with Amalgam Fillings about Toxicity of Mercury in Dental Amalgam
}

\author{
Ст Bamise, Adeleke O Oginni, Michael A Adedigba, O० Olagundoye
}

\section{ABSTRACT}

Objective: The objective of this study is to evaluate the awareness of patients with dental fillings about the toxicity of mercury in dental amalgam.

Materials and methods: Adult patients having at least one amalgam filling in their mouth were recruited in the Oral Diagnosis Department of OAUTHC, lle-Ife Dental Hospital. Participants were recruited consecutively as they report in the clinic. Data were collected using a structured questionnaire developed based on standard questions from relevant publications. They were asked to indicate the type of filling material in their mouth, ingredients of the material, previous knowledge of mercury in dental amalgam and ailments due to mercury.

They were to indicate their level of agreement with filling their cavities with dental amalgam despite prior information about its mercury content.

Results: There were about 446 respondents analyzed; male, 194 (43.5\%); female 252 (56.5\%). Six (1.4\%) and $21(4.7 \%)$ respondents were primary and secondary schools students respectively; $15(3.4 \%)$ had no formal education while about $410(91.9 \%)$ were either undergraduate or graduate. All of them had at least one amalgam filling. $249(55 \%)$ participants know the type of filling on their teeth; 156 (34.5\%) had the knowledge of the presence of mercury in dental amalgam while $26.1 \%$ believed mercury can cause problems in human beings. About $90(19.9 \%)$ participants claimed to have heard about adverse reactions to dental amalgams and $34(7.5 \%)$ of them have heard about people recovering from an illness after removal of their filling.

The level of agreement with filling their cavities with amalgam despite prior knowledge of its mercury content was $74 \%$ while $60 \%$ was observed for allowing just any material to be placed on their teeth.

Conclusion: Awareness of toxicity of mercury in dental amalgam was slightly low among the respondents studied. This may be suggested to be a reflection of nonexistent of global amalgam controversy in Nigeria.

Keywords: Patients, Toxicity, Mercury, Amalgam.

How to cite this article: Bamise CT, Oginni AO, Adedigba MA, Olagundoye 00. Perception of $P$ atients with Amalgam Fillings about Toxicity of Mercury in Dental Amalgam. J Contemp Dent Pract 2012;13(3):289-293.

\section{Source of support: Nil}

Conflict of interest: None declared

\section{INTRODUCTION}

The dental profession is one of the largest end-users of mercury ${ }^{1}$ in the form of dental amal gam. It is a dental filling material which became quite popular in the past 50 years. ${ }^{2}$ It is a mixture of mercury and silver alloy powder that solidifies at mouth temperature. It is tolerant to a wide range of clinical placement conditions and moderately tolerant to the presence of moisture during placement. The biocompatibility and durability of amalgam are good-toexcellent in large load-bearing restorations, but the silvercolored material has little esthetic value and controversy regarding its safety lingers. ${ }^{3-5}$

Some reviews of drug-induced oral reactions mentioned amal gam as capable of causing contact allergic reactions in the oral cavity and it's a primary cause of intrinsic mucosal hyperpigmentation. ${ }^{6,7} \mathrm{~A}$ mal gam was al so said to cause oral lichenoid drug reactions, although these lesions were quite uncommon. $^{8}$

A malgam use in dentistry has been embroiled in controversy for the past 3 decades, which has led to widely differing strategies. Scandinavian countries have begun to phase out the use of amalgams completely. ${ }^{9-11}$ Whereas organizations such as the A merican Dental A ssociation, the US Centres for Disease Control and Prevention, the US Public Health Service and the W orld Health Organization support the use of dental amalgam to fill cavities but with strict observance of amalgam waste protocols. ${ }^{12}$

Contention on the toxicity of amalgam stems from the fact that the restoration is composed of approximately $50 \%$ mercury. ${ }^{13}$ Very small quantities of elemental mercury vapour (less than one-half of the estimated natural daily exposure) can be released from amal gam restorations during chewing. ${ }^{14}$ 
W orldwide publicity of amal gam controversy has given rise to the current concerns regarding the safety of dental amal gam. Its discussion has grown beyond the confines of the dental profession itself and has become an emotional public health issue. ${ }^{15}$

Presently, in some countries patients are requesting replacement of their amal gam restorations. ${ }^{16}$ It has therefore been suggested that utilization of amalgam is expected to diminish as a result of public pressure and concerns over the potential risk of amalgam. This may also be due to government's concern over its environmental hazards and the successive emphasis on the use of alternative restorative materials advocated by anti-amal gamist and amalgam-free product manufacturers. ${ }^{17}$

A malgam is still predominantly used by public and private dentists in Nigeria and most of them agreed that amalgam is safe. ${ }^{18}$ Increased public awareness of these controversies surrounding amalgam is expected to arouse their health concern over the potential risk in its use and also the tendency to seek amalgam alternatives.

Few studies have centered on the awareness of nondental practitioners about the safety of amalgam. A 2006 Zogby International poll of 2,590 US adults found that $72 \%$ of respondents were not aware that mercury was a main component of dental amalgam, and $92 \%$ of respondents would prefer to be told about mercury in dental amalgam before receiving it as a filling. ${ }^{19} \mathrm{~A} 1993$ study published in FDA Consumer found that $50 \%$ of A mericans believed fillings containing mercury caused health problems. ${ }^{20}$

It is therefore, the aim of this study is to eval uate the awareness of dental patients about the toxicity of mercury in dental amalgam.

\section{MATERIALS AND METHODS}

The target population was adult patients having in their mouth at least one amalgam filling. They were recruited in the Oral Diagnosis Department of the Dental Hospital, O bafemi A wolowo U niversity Teaching H ospitals Complex, Ile-Ife, Nigeria.

Participants were recruited consecutively as they report in the clinic.

The data were collected using 2-page structured questionnaire developed based on standard, validated questions assembled from relevant publications. The study was administered by resident doctors after normal oral examination with discovery of an amalgam filling. After obtaining the consent of the patients, they were made to complete the questionnaires on the spot and retrieved immediately. No honorarium was offered.

They were asked to indicate the type of filling material in their mouth, ingredients of the material, previous know ledge of mercury in dental amalgam and ailments due to mercury.

They were also asked to indicate their level of agreement with;

1. Filling their cavities with dental amalgam despite prior information about its mercury content.

2. Filling their cavities with just any material; if no dental material can be judged to be save.

This was achieved using a Likert's scale of 'Strongly agree', 'agree', 'D on't know', 'Disagree' and 'Strongly disagree' ${ }^{21} \mathrm{~F}$ or the data analysis, the ratings for the level of agreement were assigned weight values of 5, 4, 3, 2 and 1 . The answers to each question were numerically coded and the data entered into SPSS, version 16.0.

\section{Determination of the Level of Agreement with the Use of Amalgam}

The total weight value (TWV) of agreement was obtained through the summation of the product of the number of responses for each rating and the respective weight value. This is also expressed mathematically below:

$T W V=\Sigma n . w$ (where TWV is the total weight value, $\mathrm{n}$ is the number of respondents for each rating; and $w$ is the weight assigned to the rating.

The levels of agreement $(Z)$ were arrived at by dividing the TWV by the total number of respondents (452). The values obtained ranged from 1 to 5 ; the closer the value to 5 the higher the level of agreement for amalgam use. The percentage (\%) of $Z$ was obtained by multiplying it with $20(100 / 5)$.

\section{RESULTS}

Four hundred and fifty two questionnaires were retrieved; six were discarded because they were inadequate for analysis and interpretation. There were about 446 respondents analyzed; male, 194 (43.5\%); female 252 (56.5\%). There were six (1.4\%) and $21(4.7 \%)$ respondents with primary and secondary schools education respectively; while 15 (3.4\%) had no formal education and 410 (91.9\%) were either undergraduate students or has graduated from the university. Their age ranged from 16 to 70 years (M ean 27.94, SD \pm 1.02). All the patients had amalgam filling in their mouth prior to the contact with them (Table 1).

Table 1 shows that 249 (55\%) participants know the type of filling on their teeth with almost equal percentages of male and female. 156 (34.5\%) had the knowledge of the presence of mercury in dental amalgam while $26.1 \%$ believed mercury can cause problems in human beings.

A bout 90 (19.9\%) participants claimed to have heard about adverse reactions to dental amalgams and 34 (7.5\%) 
of them have heard about people recovering from an illness after removal of their filling (Table 2).

Table 2 shows $74 \%$ agreement of the participants to allow amalgam on their teeth despite previous knowledge that it contains mercury as one of its ingredients; a slightly lower percentage $(60 \%)$ was observed for allowing just any material to be placed on their teeth as shown in Table 3.

\section{DISCUSSION}

In recent years, patients concern about the potential of dental amalgam to adversely affect their heal th has partly decreased its popularity. In Nigeria, amal gam controversy is still not been viewed as a major issue among dental practitioners and government policy makers. The extent of public awareness about this global issue is quite important and a good impetus for the progress of its debate.

The awareness of consumers of this product was evaluated in this study. A bout 35\% know that amalgam fillings contain mercury and $26 \%$ know that mercury can cause health problems in humans. This result can be said to be unacceptably low. Firstly, this is due to the fact that about $92 \%$ of the participants were either undergraduate or graduate who are privileged to have access to information. It has been suggested that consumer knowledge about mercury often paralleled the strength of policies present for addressing its use. In countries where mercury content restrictions were placed on products and the government either certified mercury-free or required mercury-free products, citizens and merchants showed often greater awareness about mercury's threat. ${ }^{22}$ Presently the authors doubt any policy on utilization of mercury in the books of the law and policies in Nigeria which might partly explain the result.

It is obvious that participants were not well informed about the type of restorations given to them. Only about $50 \%$ knew the type of filling on his/her tooth. This underscores the fact that the requirements of informed consent had not been fully satisfied in these participants and we are of the opinion that the prevalent use of amalgam

\begin{tabular}{|c|c|c|c|c|c|c|}
\hline \multirow[t]{2}{*}{ Respondents } & \multicolumn{2}{|c|}{$\begin{array}{l}\text { Do you know the type } \\
\text { of filling on your tooth }\end{array}$} & \multicolumn{2}{|c|}{$\begin{array}{l}\text { Do you know that amalgam } \\
\text { fillings contains mercury }\end{array}$} & \multicolumn{2}{|c|}{$\begin{array}{l}\text { Do you know mercury can cause } \\
\text { problems in human beings }\end{array}$} \\
\hline & Yes & No & Yes & No & Yes & No \\
\hline Male $(n=197)$ & $109(55.3)$ & 88 & $67(34.0)$ & 130 & $49(24.9)$ & 148 \\
\hline Female $(n=255)$ & $140(54.9)$ & 115 & $89(34.9)$ & 166 & $69(27.1)$ & 186 \\
\hline Total & $249(55)$ & & $156(34.5)$ & & $118(26.1)$ & \\
\hline$\chi^{2}, d f, p$ & $\begin{array}{c}\chi=0.008 \\
d f=1 \\
p=0.928\end{array}$ & & $\begin{array}{c}\chi=0.039 \\
d f=1 \\
p=0.843\end{array}$ & & $\begin{array}{c}\chi=0.275 \\
d f=1 \\
p=0.600\end{array}$ & \\
\hline
\end{tabular}

\begin{tabular}{lccc}
\multicolumn{4}{c}{ Table 2: Level of agreement with accepting dental amalgam despite prior knowledge of its mercury content } \\
\hline Ratings of level of & $\begin{array}{c}\text { No. of respondents } \\
\text { ( })\end{array}$ & $\begin{array}{c}\text { Weight of the ratings } \\
\text { (w) }\end{array}$ & Contribution of each rating \\
agreement & 12 & 1 & 12 \\
\hline Strongly disagree & 33 & 2 & 66 \\
Disagree & 139 & 3 & 417 \\
Don't know & 186 & 4 & 444 \\
Agree & 82 & 5 & 1649 \\
Strongly agree & & & 10 \\
\hline Total
\end{tabular}

Level of agreement $=\frac{1649}{452}=3.7=74 \%$

\begin{tabular}{|c|c|c|c|}
\hline $\begin{array}{l}\text { Levels of } \\
\text { agreement }\end{array}$ & $\begin{array}{l}\text { No. of respondents } \\
\text { (n) }\end{array}$ & $\begin{array}{l}\text { Weight of the ratings } \\
\text { (w) }\end{array}$ & Contribution of each rating \\
\hline Strongly disagree & 44 & 1 & 44 \\
\hline Disagree & 129 & 2 & 258 \\
\hline Don't know & 124 & 3 & 372 \\
\hline Agree & 111 & 4 & 444 \\
\hline Strongly agree & 44 & 5 & 220 \\
\hline Total & & & 1338 \\
\hline
\end{tabular}

Level of agreement $=\frac{1338}{452}=3.0=60 \%$ 
in Nigerian dental hospitals had possibly shrouded the prescription of alternatives. There are several alternatives to amalgam..$^{23} \mathrm{~A}$ pparently, none of them are economically available at the present as compared to amalgam; a similar statement made by $\mathrm{K}$ hairuldean and Sadiq ${ }^{24}$ in Saudi A rabia.

On the other hand, practising dentist must communicate with their patients about risks (amalgam in this case); this is one of the challenges faced because discrepancies exist in their beliefs. Communicating information about risks to patients has been described as a difficult task. ${ }^{25}$ Nevertheless, while consumer knowledge about risks associated with mercury in mercury-containing fillings is low, the dental profession has been said to be wellinformed. ${ }^{26}$

The cost and difficult mode of acquisition of mercuryfree products is also an issue in Nigeria which is similar to the findings of U ram et al; ${ }^{21}$ Dentists in K enya, Senegal, China, India, Brazil and M exico indicated that mercuryfree materials were more expensive to acquire. They required more time to place and are of increasing costs to patients.

Despite its acknowledged health hazards, amalgam was popular among the respondents. Although $60 \%$ agree they would not allow just any material to be placed on their teeth, about $74 \%$ agree that they would still have allow ed amal gam to be placed on their teeth even with prior knowledge that it contains mercury. This shows the popularity of amalgam and probably the only filling material they are familiar with. It is also supported by a study by Udoye and $\mathrm{Aguwa}^{18}$ in 2008 about the attitude of Nigerian dentists on amalgam safety; they concluded that amalgam is well accepted by both dentists and patients in the studied population.

In most countries, the mass media has always been at the forefront of amalgam controversy before the dental professions take positions. It is evident also that the local media in Nigeria has not focused the public attention to adverse health effect of mercury or the global amalgam controversy and this underscore the weak impact dental health issues reportage was having on the country's consumers.

The 'Harmful substances and hazardous wastes' subprogram of UNEP was established to assists countries and regions in managing, within a life-cycle approach, chemical substances and waste that have potential to cause adverse impact on environment and human health. This body recognizes mercury as a chemical agent that can produce a range of adverse human health effects. UNEP has been working to address mercury issues since 2003; to develop a global legally binding instrument on mercury, form UNEP Global M ercury Partnership is to protect human heal th and the global environment from the release of mercury and its compounds by minimizing and, where feasible, ultimately eliminating global anthropogenic mercury releases to air, water and land. ${ }^{27} \mathrm{~N}$ igeria should key-in to these programs. Further down the ladder the Nigerian Dental A ssociation should become UNEP partner so as to effectively deliver mercury activities, i.e. Priorities of action or partnership area as enumerated.

The world is fast becoming one big global village and before amalgam becomes a big issue and its controversy pervades our society, we wish to recommend the encouragement of best management practices for operative procedures. Nigerian dentists should al so adopt the concept that requires an explanation and discussion with the patient about the scientific evidences regarding amal gam safety and the potential risks from amalgam removal. The Nigerian Dental A ssociation should take a leading role in awarenessraising; sponsoring of clinical and epidemiological researches; championing the course of getting economical alternatives to amalgam imported into the country and the training of dental professionals to adopt the best practices for amalgam waste management in the dental setting. ${ }^{28}$

\section{CONCLUSION}

The dental team and health policy makers in Nigeria must begin to look for alternative to mercury containing dental fillings ahead of possible patients' awareness of the adverse effect of mercury in humans. This may lead to rejection of such treatment options. Also, all possible barriers to the use of mercury free dental fillings must be removed or controlled to enable such to be used as a better alternative among dental offices in Nigeria.

\section{REFERENCES}

1. Horsted-Bindslev P. A malgam toxicity-environmental and occupational hazards. J ournal of D entistry 2004;32:359-65.

2. Council on Scientific A ffairs, A merican Dental A ssociation. D ental amal gam: U pdate on safety concerns. JA DA 1998;129: 494-503.

3. Fuks $A B$. The use of amalgam in pediatric dentistry. Pediatr Dent 2002;24(5):448-55.

4. N eedleman HL. M ercury in dental amal gam: A neurotoxic risk? J AM A 2006;295(15):1835-36.

5. Osborne JW, Summitt JB, Roberts HW. The use of dental amalgam in pediatric dentistry: R eview of the literature. Pediatr Dent 2002;24(5):439-47.

6. A bdollahi M, Rahimi R, Radfar M. Current Opinion on D ruginduced Oral Reactions: A Comprehensive Review. J Contemp Dent Pract $2008 \mathrm{M}$ arch;(9)3:001-015.

7. A bdollahi M, Radfar M. A review of drug-induced oral reactions. J Contemp Dent Pract 2003;4(1):10-31.

8. Laeijendecker R, Dekker SK, Burger PM, M ulder PG, V an J oost T, N eumann M H. O ral lichen planus and allergy to dental amalgam restorations. A rch Dermatol 2004;140(12):1434-38. 
9. Swedish Council for Planning and Coordinating R esearch (FRN) Stockholm. Report No 2652, 19 Feb, 1998. Helsetilsynet (N orwegian B oard of Health Supervision).

10. L undberg S. Swedish views on questions put at the stakeholder meeting concerning the mercury export ban and storage obligations of mercury 8th Sep, 2005. Brussels, European Commission, M inistry of Sustainable Development, Division for Eco-management and Chemicals, 2005.

11. A nderson BA, A renholt-Bindslev D, Cooper IR, David P, Ecker $P$. Dental amalgam: $A$ report with reference to the medical devices directive 93/42/EEC from an A d H oc Working Group mandated by DGIII of the European Commission. Angelholm, Sweden, Nordiska Dental AB, 1998.

12. A-Z topics: Best management practices for amalgam waste. A merican Dental A ssociation (online article) (http://www.ada. org/prof/resources/topics/amalgam_bmp.asp, accessed 26 A ug, 2009).

13. M ackert JR. Dental amalgam and mercury. J A m Dent A ssoc 1991;122:54-61.

14. Berglund A. Estimation by a 24-hour study of the daily dose of intraoral mercury vapor inhaled after release from dental amalgam. J Dent Res 1990;69:1646-51.

15. ReinhardtJW. Risk assessment of mercury exposure from dental amalgams. J Public Health Dent 1988;48(3):172-77.

16. Chiodo GT, Tolle SW . Can a patient make an irrational choice? The dental amalgam controversy. Gen Dent 1992;40:186-87.

17. Widstrm $E$, Forss $H$. Selection of restorative materials in dental treatment of children and adults in public and private dental care in Finland. Swed Dent J 1994;18:1-7.

18. C U doye, E A guwa. A malgam safety and dentists. A ttitude: A survey among a subpopulation of N igerian Dentists. Operative Dentistry 2008;33(4):467-71.

19. What patients don't know: Dentists' sweet tooth for mercury. M ercury policy project. 14 Feb, 2006. (http://mpp.cclearn.org/ wp-content/uploads/2008/08/whatpatientsdontknow 1.pdf. Accessed 19 A pr, 2011).

20. Bradbard, Laura. Dental amalgam: Filling a need or foiling health? (Dec 1993) FDA consumer 27: 22. (http://findarticles. com/p/articles/mi_m1370/is_n10_v27/ai_14891423/. A ccessed 17 Sep, 2010).

21. Likert R. N ew patterns of management. New Y ork: M cGrawHill 1961.
22. U ram E, Bischofer BP, Hagemann S. M arket analysis of some mercury-containing products and their mercury-free alternatives in selected regions. (http://www.ipen.org/ipenweb/documents/ ipen\%20documents/grs253.pdf. A ccessed 24 Jan, 2011)

23. Christensen $G$ J . A re there alternatives to dental amal gam? J A m Dent A ssoc 1991;122(3):77.

24. K hairuldean N, Sadig W M. A malgam safety and alternative restorative materials: A cross sectional survey among dentists. The Saudi Dental Journal 1996;8(1):27-33.

25. Slovic P. Informing and educating the public about risk. Risk A nal 1986;6:403-15.

26. M ercury policy project what patients don't know : D entists' sweet tooth for mercury (www.mercurypolicy.org or www. cleanwateraction.org/mercury. A ccessed on $10 \mathrm{M}$ ar, 2011).

27. Chemicals: M ercury programme. U nited N ations Environmental Programme (http://www.unep.org/hazardoussubstances/ M ercury/tabid/434/D efault.aspx. A ccessed on 19th J an, 2012).

28. A dedigba MA, A fon A, A begunde AA, N whator SO, Bamise CT. A ssessment of dental waste management in a Nigerian tertiary hospital. W aste $M$ anagement and Research 2010;28:769-77.

\section{ABOUT THE AUTHORS}

\section{CT Bamise (Corresponding Author)}

Senior L ecturer, Department of Restorative Dentistry, Obafemi A wolowo University, Osun State, N igeria, e-mail: bamisect@yahoo.com

\section{Adeleke O Oginni}

Associate Professor, Department of Restorative Dentistry, Obafemi A wolowo U niversity, Osun State, Nigeria

\section{Michael A Adedigba}

Senior Lecturer, Department of Preventive Dentistry, Obafemi A wolowo U niversity, Osun State, Nigeria

\section{OO Olagundoye}

Senior Registrar, Department of Preventive Dentistry, Obafemi A wolowo U niversity, Osun State, Nigeria 